\title{
Identification, surveillance and management of Aedes vexans in a flooded river valley in Nottinghamshire, United Kingdom
}

\author{
A.G.C. Vaux ${ }^{1 *}$ iD , D. Watts ${ }^{2}$, S. Findlay-Wilson ${ }^{3}$, C. Johnston ${ }^{1}$, T. Dallimore ${ }^{4}$, P. Drage ${ }^{5}$ and J.M. Medlock ${ }^{1}$ \\ ${ }^{1}$ Medical Entomology and Zoonoses Ecology group, Public Health England, Porton Down, Salisbury, SP4 0JG, United \\ Kingdom; ${ }^{2}$ Bassetlaw DC Environmental Health, Queens Buildings, Potter Street, Worksop, S80 2AH, United Kingdom; \\ ${ }^{3}$ Virology and Pathogenesis Research Group, National Infection Service, Public Health England, Porton Down, Salisbury, \\ SP4 0JG, United Kingdom; ${ }^{4}$ Department of Biology, Edge Hill University, Ormskirk, L39 4QP, United Kingdom; ${ }^{5}$ Buzzoff \\ Pest Solutions, 6 Priory Close, Doncaster, South Yorkshire, DN10 5HS, United Kingdom; alexander.vaux@phe.gov.uk
}

Received: 26 March 2021 / Accepted: 30 June 2021

(c) 2021 A.G.C. Vaux et al.

\section{RESEARCH ARTICLE}

\begin{abstract}
Aedes vexans is known to occur in large populations in riverine floodplains in much of Europe, where it can cause a significant biting nuisance and is often subject to large scale control strategies. Until recently it had only been reported in very small numbers in the United Kingdom. After receiving reports of nuisance biting near the river Idle, Nottinghamshire (East Midlands, England), mosquito surveillance was conducted over three years (2018-2020) using Mosquito Magnet adult traps. Ae. vexans was found in all years, in very high numbers, particularly in 2020, reaching a peak of almost 5,000 female mosquitoes per trap night, the highest reported density of trapped adult mosquitoes in the UK. Larval control was conducted in all years, and adult control in one year, however local peculiarities of flood and water management presents challenges and necessitates a multi-faceted approach. Strategies for further expansion of the control operation by developing strategies for water management, coupled with larval surveys to define the extent and seasonality of larval habitats, and application methods of Bacillus thuringiensis israelensis products are discussed.
\end{abstract}

Keywords: Aedes vexans, mosquito control, vector-borne diseases, mosquito, United Kingdom

\section{Introduction}

Aedes (Aedimorphus) vexans (Meigen, 1830) is a polycyclic mosquito species breeding predominantly in inundated areas such as floodplains of rivers and lakes with fluctuating water levels. In temporary flooded wet meadow and swamp habitats in continental Europe, the species can develop large populations, and can cause a significant biting nuisance (Becker, 1989). Larval development can be rapid in temporary water bodies that remain wet from just a few days to several weeks, such as flooded meadows, and low-lying areas with willow and reed (Becker et al., 2003).

Aedes vexans adult females can cause a severe nuisance and can become highly abundant where the flooding regime favours egg hatching and larval development (Becker et al., 2003). Each female mosquito can lay 100 eggs and take multiple bloodmeals. Eggs can hatch shortly after flooding if the water temperature exceeds $9^{\circ} \mathrm{C}$, with larval development as rapid as 1 week at $30^{\circ} \mathrm{C}$ and up to 3 weeks at $15^{\circ} \mathrm{C}$. Eggs can survive for up to 5 years if no flooding occurs after oviposition, with eggs normally spending the colder months (September to March) in diapause. Upon flooding, eggs hatch in response to oxygen depletion and not all eggs hatch synchronously, with the species adopting instalment hatching to maximise the survival of the populations should aquatic habitats dry out before adult emergence. Where conditions support development, huge numbers of larvae can be found, with hundreds per litre and more than 100 million per hectare. This mass 
emergence creates pressure for seeking blood meals and females may be forced to migrate up to $15 \mathrm{~km}$ from their breeding sites, with these founder sites leading to significant migration to other potential habitats (Becker et al., 2003; Petrić et al., 1999).

In some parts of Europe, particularly after flooding events, $A$ e. vexans can become a very abundant nuisance species, often during the daytime, particularly along the river valleys of central Europe (Becker et al., 2003). In the Upper Rhine Valley, Ae. vexans is the most abundant species found in riverine floodwater habitat, making up more than $90 \%$ of the populations during summer (Becker, 1997). In Europe, the mosquito has been implicated in the transmission of Tahyna virus (TAHV) (Bardos and Danielova, 1959; Medlock et al., 2007; Napp et al., 2018) and further afield in Africa, it is a notable vector of Rift Valley fever virus (RVFV) (Miller et al., 2002). It is also considered a vector of Dirofilaria in Europe (Fortin and Slocombe, 1981; Hendrix et al., 1980). Although it is considered a vector elsewhere within its range, there is no reason to suspect that this species is involved in any disease transmission in the UK. However, owing to its known nuisance habits, it is likely to present a biting nuisance locally.

Although Ae. vexans has always been included in the list of British mosquitoes on account of several historical records in England and Wales, there is no evidence that these records constituted a significant nuisance population. However, in 2017 host-seeking females and nuisance biting were reported in Norwich. Subsequent surveys identified Ae. vexans larvae breeding in floodwater habitat at Marston Marsh on the flooded valley of the River Yare (Norfolk). This was considered the first notable population of Ae. vexans in England for 90 years (Medlock et al., 2017).

In the same year, nuisance biting reports from a resident of Gamston village, Nottinghamshire, were made to the local environmental health officer during spring / early summer (Medlock et al., 2017). Locally there had been reports of mosquito biting in the village since the early 1990s, however the source of the biting had never been identified, nor had the species responsible for the biting. Mosquito samples collected by a resident of Gamston were confirmed as $A e$. vexans, both by morphological and molecular techniques. This study reports on adult mosquito trapping in and near the village of Gamston in Nottinghamshire in the East Midlands of England, conducted from 2018-2020 in order to characterise the mosquito population, and details control efforts and viral analysis of mosquitoes.

\section{Materials and methods}

\section{Mosquito surveillance}

Adult mosquito trapping was conducted 2018-2020 in and close to the village of Gamston (Figure 1). Gamston village (approximate population of 2,000 people; latitude 53.278, longitude -0.936), in the county of Nottinghamshire two miles south of the town of Retford, is situated on an elevated slope above and to the east of the low-lying valley of the River Idle, close to the confluence with the rivers Maun and Poulter, part of the River Trent catchment. It lies close to an area previously active for underground coal mining, which is considered to have led to subsidence in the river valley and the creation of flooded areas.

Mosquito Magnet ${ }^{\circ}$ Executive mosquito traps (MosquitoMagnet, Lititz, PA, USA) with octenol (MosquitoMagnet) were deployed to Gamston from 2018-2020. Mosquito Magnet traps were chosen on account of their proven ability to trap large numbers of mammal biting mosquitoes in the $\mathrm{UK}$, and are able to run for consecutive nights without servicing or maintenance (Hutchinson et al., 2007; Medlock and Vaux, 2015; Vaux et al., 2015).

In the first year (year 1; 2018) two adult traps were run by local residents at the south-western corner of the village (site A, traps 1 and 2), and in year 2 (2019), a single adult trap was run at the nearby Gamston Airport (site B), approximately 400 metres west of the River Idle. In year 3 (2020), an adult trap was run at a dwelling (site C), 200 metres west of the river, and within 20 metres of flooded wetland habitat.

In 2018, the adult traps were run on two occasions in July and August, totalling 11 trap nights to confirm the cause of the nuisance biting and to investigate the mosquito diversity. In 2019, at site B an adult trap was run on alternate weeks for four nights from week 16-42 (April to October) to ascertain the seasonality of mosquito activity in the river valley. In 2020, having identified the source of the mosquito breeding, the trap at site $\mathrm{C}$ was run on alternate weeks for four nights from week 21-43 (May to October) to assess both seasonality and abundance, and to inform control efficacy.

Results are also reported from a resident at site A in 2020, with a trap running at the same location as A1 in 2018 but the data are not included in the figures as the collection dates are estimated. All mosquito samples collected by both local villagers and local authority officials were sent to medical entomologists at Public Health England for identification, and mosquitoes were identified morphologically using available keys (Snow, 1990). 


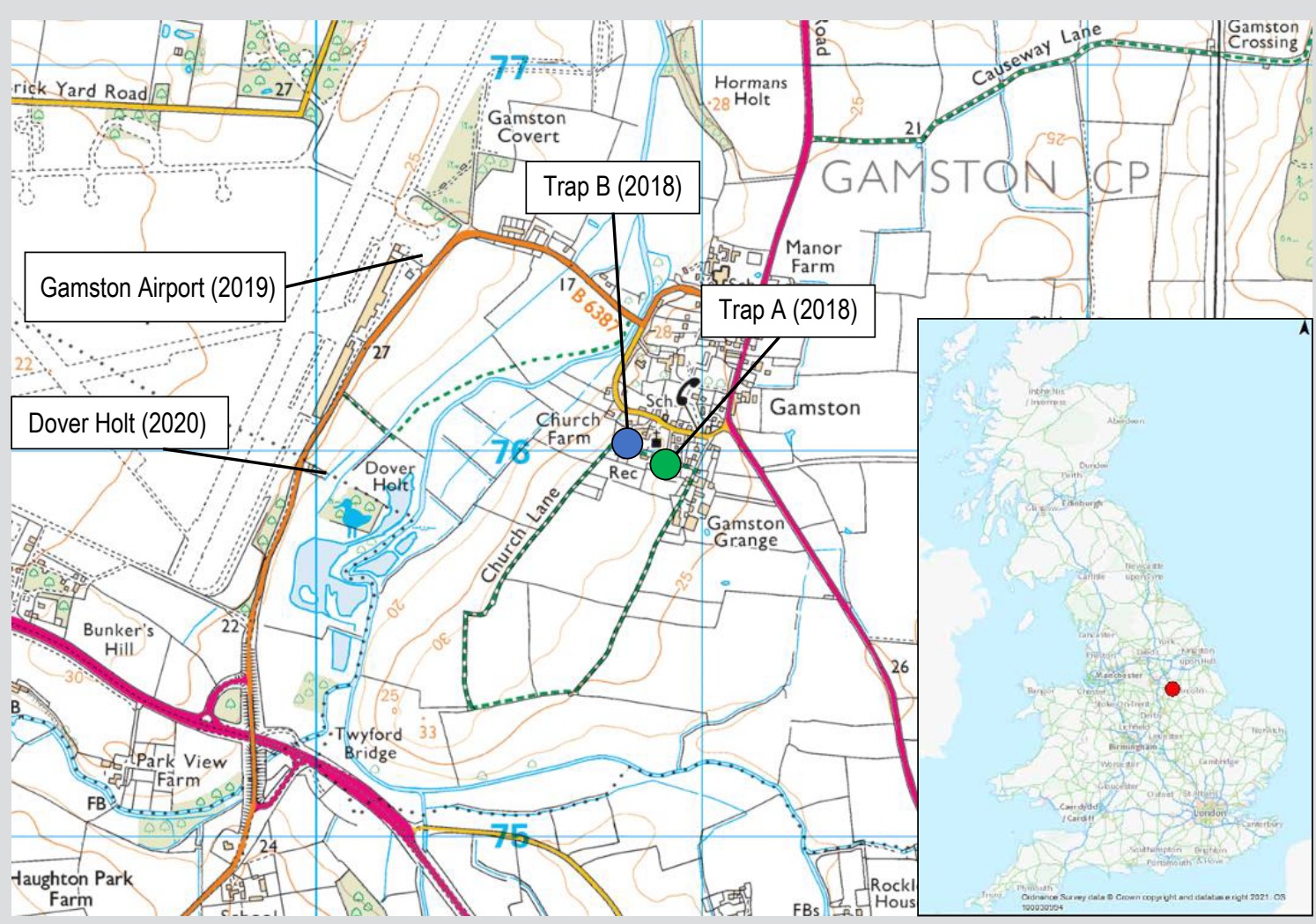

Figure 1. Map of Gamston village and wetland habitat south-west of the village. Inset map of Great Britain with approximate location of Gamston indicated as a red maker.

Mosquitoes were grouped as follows if poor condition or further analysis by other methods (e.g. DNA analysis; examination of male characters) was required to identify to species: species from the Anopheles maculipennis complex; Aedes cantans/annulipes (Aedes (Ochlerotatus) cantans (Meigen, 1818), Aedes (Ochlerotatus) annulipes (Meigen, 1830); Aedes cinereus/geminus (Aedes (Aedes) cinereus Meigen, 1818, Aedes (Aedes) geminus Peus, 1970); Culex pipiens complex.

Adult mosquito abundance was calculated per trap night, and expressed as mean number of adults per trap night for each survey week $\left(\mathrm{X} / \mathrm{n}^{\mathrm{w}}\right)$ and the mean abundance per night across all trap nights that year $\left(\mathrm{X} / \mathrm{n}^{\mathrm{s}}\right)$ in accordance with Medlock and Vaux (2015).

In 2020, when numbers exceeded the capability of individual counting, $100 \mathrm{Ae}$. vexans were counted out and weighed using a laboratory balance (Fisher Scientific SG-402; Fisher Scientific UK Ltd, Loughborough, UK; $402 \times 0.01 \mathrm{~g}$ ). This was repeated 10 times, and a mean mass of 100 adult mosquitoes calculated, and used to estimate the number of mosquitoes present in the sample bag.

\section{Molecular identification}

Molecular identification of Ae. vexans specimens was undertaken by comparing a $700 \mathrm{bp}$ region of the DNA barcoding cytochrome oxidase subunit I (COI) gene to matched sequences within the GenBank database, using the $\mathrm{BLAST}^{\circ}$ function (NCBI). DNA was extracted from specimens by homogenising two legs with an electronic pestle followed by isolation using DNeasy ${ }^{\circledR}$ Blood and Tissue Kits (69506, Qiagen, Manchester, UK) in accordance to the manufacturer's instructions. The COI gene was targeted for amplification by direct (non-cloned) polymerase chain reaction (PCR) using previously published primer set (Folmer et al., 1994), where PCR reactions consisted of 2.5-20 ng of DNA template, $0.5 \mathrm{U}$ of Phusion ${ }^{\circledR}$ HighFidelity Polymerase (New England Biolabs ${ }^{\circledR}$ Ltd. (NEB), Herts, UK), $1 \times$ Phusion HF Buffer (NEB), $200 \mu$ M of dNTP mix (NEB), $0.5 \mu \mathrm{M}$ each primer, and 2\% DMSO (NEB). PCR amplification was performed using a primer thermal cycler (Techne, Staffordshire, UK) programmed with an initial denaturation of $98^{\circ} \mathrm{C}$ for $30 \mathrm{~s}$, followed by 35 cycles of $98^{\circ} \mathrm{C}$ for $10 \mathrm{~s}$ for denaturation, $20 \mathrm{~s}$ of annealing at $53^{\circ} \mathrm{C}$, and $72{ }^{\circ} \mathrm{C}$ for $20 \mathrm{~s}$ extensions, followed by a final extension of $72^{\circ} \mathrm{C}$ for $7 \mathrm{~min}$. Sequencing reactions were undertaken using the BigDye ${ }^{\mathrm{mt}}$ Terminator v.3.1 Cycle Sequencing Kit 
(4337455, Applied Biosystems ${ }^{\bullet}$ (AB), Paisley, UK) and DNA visualised using an $\mathrm{AB} 3500$ genetic analyser.

\section{Testing for Tahyna virus}

The analysis of Ae. vexans for the presence of TAHV was performed using a primer/probe set targeting the S segment of Tahyna virus (Weidmann et al., 2003). Ninety-six Precellys tubes (MK28, Labtech International, Heathfield, UK) each containing fifty Ae. vexans (total of $4,800 \mathrm{Ae}$. vexans adult females) were resuspended in 600 $\mu \mathrm{l}$ of RLT buffer $+\beta$-mercaptoethanol and homogenised (Precellys 24 High-Powered Bead Mill Homogenizer, Labtech International, Heathfield, UK) using $3 \times 20 \mathrm{~s}$ bursts of $5,000 \mathrm{rpm}$. After addition of $600 \mu \mathrm{l}$ of $70 \%$ ethanol the samples were centrifuged at 5,000 rcf for $1 \mathrm{~min}$ and the supernatant processed through a QIAshredder (79656, Qiagen, Manchester, UK) at 16,000 $\mathrm{rcf}$ for $2 \mathrm{~min}$. Total RNA was extracted using the RNeasy Mini Kit (74106, Qiagen) in accordance with the manufacturer's instructions. A reverse compliment TAHV RNA standard was synthesised (Integrated DNA Technologies, Leuven, Belgium) covering the 102 bp region of the $S$ segment targeted by the primer/ probe set to serve as a positive control and for quantification. RT-PCR was performed using the Invitrogen SuperScript III Platinum One-Step qRT-PCR Kit (11732088, Thermo Fisher Scientific, Hemel Hempstead, UK) on the QuantStudio 7 Flex Real-Time PCR platform, using standard cycling conditions for SSIII.

\section{Results}

\section{Mosquito surveillance}

In the first year (year 1;2018), sampling commenced in week 30 (week commencing (wc) $23^{\text {rd }}$ July) with $337 \mathrm{Ae}$. vexans collected over 7 trap nights at trap A1 - a mean number of females per night of $48.14 \mathrm{n}^{\mathrm{w}}$ (Table 1; Figure 2). During the subsequent survey week, in week 32 (wc $6^{\text {th }}$ August), 114 Ae. vexans $\left(28.5 \mathrm{n}^{\mathrm{w}}\right)$ were caught at trap A1 and $330\left(82.5 \mathrm{n}^{\mathrm{w}}\right)$ at trap A2 (Figure 2), totalling 451 adult Ae. vexans for trap $1\left(41 \mathrm{n}^{\mathrm{s}}\right)$, and 330 for trap $2\left(82.5 \mathrm{n}^{\mathrm{s}}\right)$. Additional species caught at traps A1 and A2 in 2018 were identified in much smaller numbers (Ae. cantans/annulipes $\left(\mathrm{n}=5,0.33 \mathrm{n}^{\mathrm{s}}\right)$, Aedes (Ochlerotatus) caspius (Pallas, 1771) $\left(\mathrm{n}=1,0.13 \mathrm{n}^{\mathrm{s}}\right)$, Aedes (Dahliana) geniculatus (Olivier, 1791) $\left(\mathrm{n}=1,0.14 \mathrm{n}^{\mathrm{s}}\right)$, Aedes (Ochlerotatus) punctor (Kirby, 1837) $\left(\mathrm{n}=2,0.29 \mathrm{n}^{\mathrm{s}}\right)$, Aedes (Rusticoidus) rusticus (Rossi, 1790) $\left(\mathrm{n}=1,0.14 \mathrm{n}^{\mathrm{s}}\right)$, Anopheles (Anopheles) claviger Meigen, 1804, $\left(\mathrm{n}=38,2.53 \mathrm{n}^{\mathrm{s}}\right)$; Anopheles (Anopheles) plumbeus Stephens, 1828, $\left(\mathrm{n}=1,0.14 \mathrm{n}^{\mathrm{s}}\right)$, Anopheles maculipennis s.l. (Meigen, 1818) $\left(\mathrm{n}=14,0.93 \mathrm{n}^{\mathrm{s}}\right)$, Coquillettidia (Coquillettidia) richiardii (Ficalbi, 1889) $\left(\mathrm{n}=5,0.71 \mathrm{n}^{\mathrm{s}}\right)$, Culex pipiens s.l. Linnaeus, $1758,\left(\mathrm{n}=6,0.4 \mathrm{n}^{\mathrm{s}}\right)$, and Culiseta (Culiseta) annulata (Schrank, 1776) $\left(\mathrm{n}=9,0.6 \mathrm{n}^{\mathrm{s}}\right)$. These
Table 1. Total number of adult female mosquitoes shown by year and species across all traps. $2018=11$ trap nights; 2019 $=45$ trap nights; $2020=48$ trap nights. 2018-2020 = total of 104 trap nights. Note that in 2020, mosquito samples were weighed and extrapolated.

\begin{tabular}{lrrrr} 
Species & $\mathbf{2 0 1 8}$ & $\mathbf{2 0 1 9}$ & $\mathbf{2 0 2 0}$ & \multicolumn{1}{c}{ Total } \\
Aedes cantans/annulipes & 5 & 3 & 4 & 12 \\
Aedes caspius & 1 & 200 & & 201 \\
Aedes cinereus/geminus & & 1 & & 1 \\
Aedes geniculatus & 1 & & & 1 \\
Aedes punctor & 2 & & & 2 \\
Aedes rusticus & 1 & & 12 & 13 \\
Aedes sticticus & & 134 & & 134 \\
Aedes vexans & 781 & 3,108 & 78,206 & 82,095 \\
Anopheles claviger & 38 & 17 & 13 & 68 \\
Anopheles maculipennis s.l. & 14 & 1 & & 15 \\
Anopheles plumbeus & 1 & 1 & & 2 \\
Coquillettidia richiardii & 5 & & & 5 \\
Culex pipiens s.l. & 6 & 3 & & \\
Culiseta annulata & 9 & 11 & 8 & 9 \\
Total & 864 & 3,479 & 78,243 & 82,586
\end{tabular}

initial surveys confirmed a significant abundance of $A e$. vexans and residents confirmed significant nuisance which warranted further investigation.

A field visit was conducted during week 34 (wc $20^{\text {th }}$ August), which coincidentally coincided with the cessation of adult mosquito activity, as communicated by a local resident. Several sites were visited during the site visit, both around the village; all of which were considered to be unsuitable for $A e$. vexans. Field visits were also conducted to the southwest of the village in low-lying land (subject to seasonal flooding) and lakes either side of the River Idle, more typical of Ae. vexans habitat. Although all flooded grassland areas were dry, it seemed likely that these low-lying flood zones could potentially support the high numbers of Ae. vexans in Gamston (Figure 3).

During the following year, in year 2 (2019), the Mosquito Magnet trap at site B (Gamston airport) which ran from weeks 15 (wc $15^{\text {th }}$ April) to week 42 (wc $14^{\text {th }}$ October) (Figure 4; Table 1) recorded its first adult mosquito ( $A n$. claviger) in week 24 (wc $10^{\text {th }}$ June). Adult Ae. vexans were not caught in the trap until week 28 (wc $8^{\text {th }}$ July), with a mean abundance of $121.75 \mathrm{n}^{\mathrm{w}}(\mathrm{n}=487)$. Densities of trapped Ae. vexans continued to rise to a first peak in week $30\left(171 \mathrm{n}^{\mathrm{w}}\right)$, followed by a drop in density in week $32\left(29 \mathrm{n}^{\mathrm{w}}\right)$, and then a second peak in density of $396.25 \mathrm{n}^{\mathrm{w}}$ in week 34 (wc $19^{\text {th }}$ August). Thereafter, numbers of $A e$. vexans declined, with the final adult captured in week 40 (wc $30^{\text {th }}$ September), with none found in week 42 . Over 


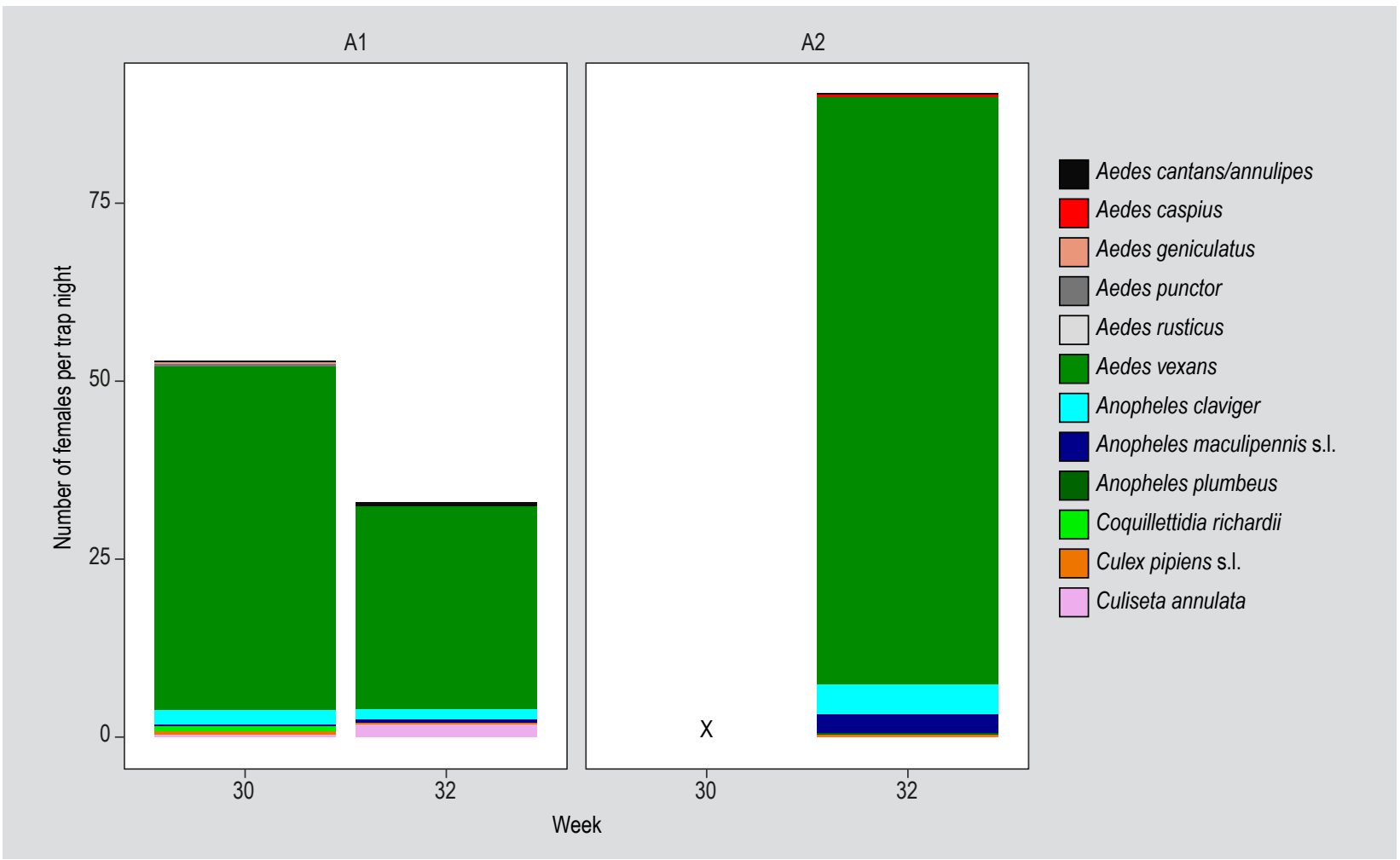

Figure 2. Number of adult female mosquitoes per trap night shown by week number, by two Mosquito Magnet traps (site A, traps 1 and 2), both located on Church Lane, Gamston, UK, in 2018. ' $X$ ' indicates trap did not run that week.
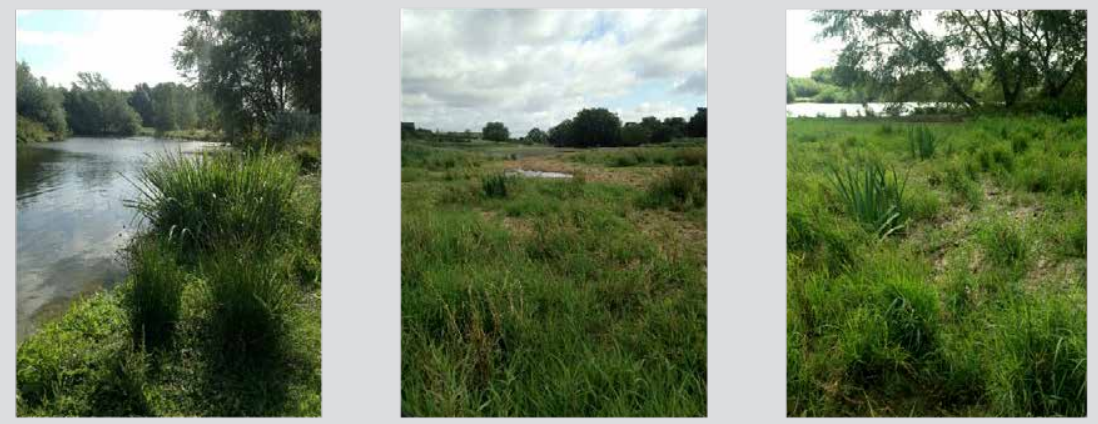

Figure 3. The River Idle and surrounding wetlands, south-west of the village of Gamston, Nottinghamshire, UK.

28 trap nights in 2019, a total of 3,108 Ae. vexans were trapped $\left(111 \mathrm{n}^{\mathrm{s}}\right)$, with a distinct seasonality centred around weeks 28-38. This species clearly dominates over all other mosquito species.

In year 3 (2020), the first adult mosquitoes were collected at the trap at site $C$ in week 21 (wc $18^{\text {th }}$ May) were $A n$. claviger $\left(\mathrm{n}=8,2 \mathrm{n}^{\mathrm{w}}\right)$, Ae. cantans/annulipes $\left(\mathrm{n}=4,1 \mathrm{n}^{\mathrm{w}}\right)$, and Cs. annulata $\left(\mathrm{n}=2,0.5 \mathrm{n}^{\mathrm{w}}\right)$ (Figure 5; Table 1). Similar numbers of An. claviger ( $\left.\mathrm{n}=4,1 \mathrm{n}^{\mathrm{w}}\right)$ and Cs. annulata $(\mathrm{n}=6$, $1.5 \mathrm{n}^{\mathrm{w}}$ ) were trapped in week 23. Ae. vexans appeared in traps in week 25 (wc $15^{\text {th }}$ June) in very high numbers, totalling $\sim 19,900\left(4,975 \mathrm{n}^{\mathrm{w}}\right)$; three weeks earlier than in year 2 (2019), and the largest estimated catch rate reported during 2018-2020 (Figure 6). Numbers of trapped female Ae. vexans remained high during week $27\left(3,633.75 \mathrm{n}^{\mathrm{w}}\right)$, before declining rapidly to week 29 (mid-late July; week 29, $687.5 \mathrm{n}^{\mathrm{w}}$; week $31,802.5 \mathrm{n}^{\mathrm{w}}$ ). In mid-late August, there was a second peak of trapped female Ae. vexans, with 4,500 $\mathrm{n}^{\mathrm{w}}$ trapped in week 35 , remaining at high densities into midSeptember, before declining by the end of October. At site C, over 40 trap nights in 2020, a total of 78,206 Ae. vexans were estimated to have been trapped $\left(1,955 \mathrm{n}^{\mathrm{s}}\right)$. Additional samples were received from site A in week 24 (estimated 


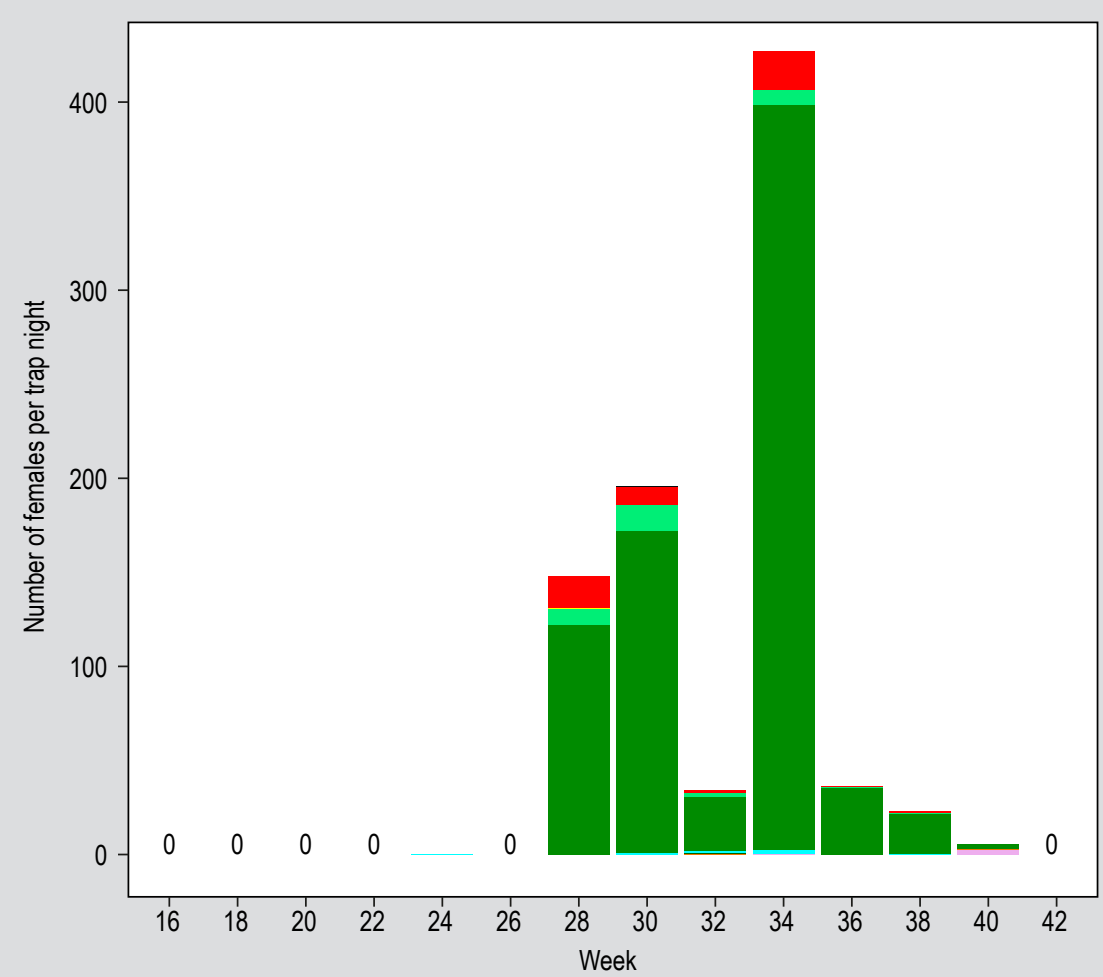

Aedes cantans/annulipes Aedes caspius $\square$ Aedes cinereus/geminus $\square$ Aedes sticticus Aedes vexans Anopheles claviger Anopheles maculipennis s.I. Anopheles plumbeus Culex pipiens s.l. Culiseta annulata

Figure 4. Number of adult female mosquitoes per trap night shown by week number, by a Mosquito Magnet trap located at site B (Gamston Airport, UK), 2019. ' 0 ' indicates trap running with no mosquitoes collected. In week 24, one Anopheles claviger was collected but the number is too small to show on the figure.

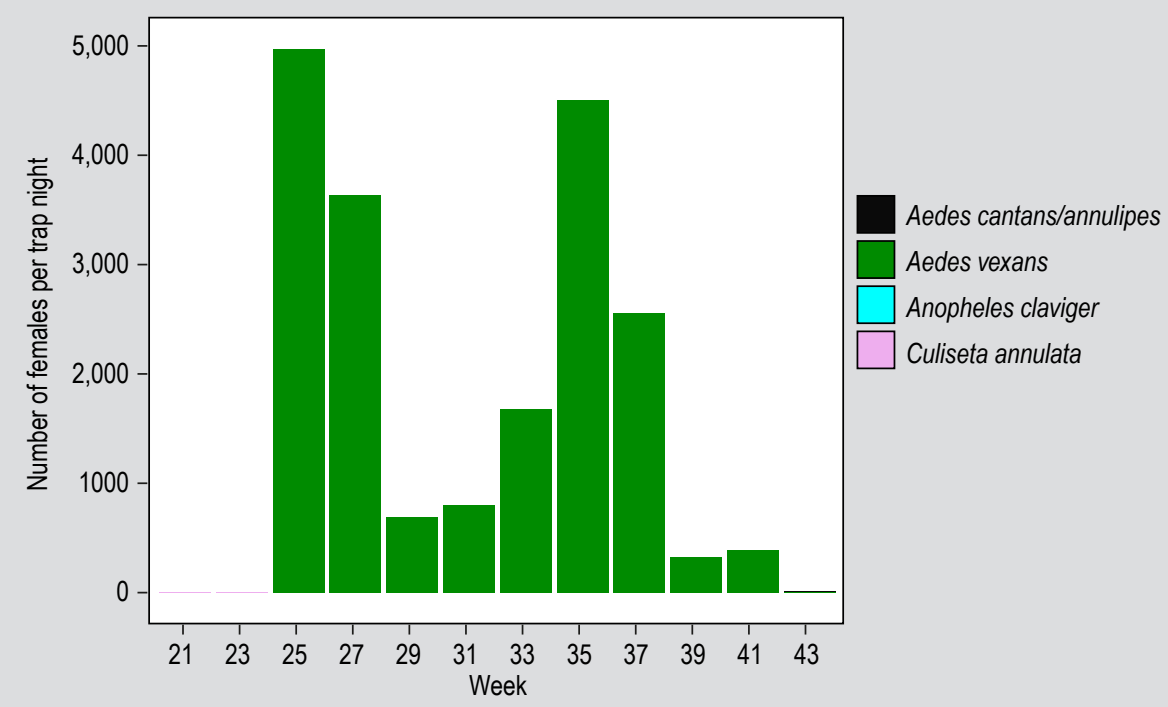

Figure 5. Number of adult female mosquitoes per trap night shown by week number, by a Mosquito Magnet trap located at site C, 2020. Numbers of some species in weeks 21,23 , and 43 are too small to show on the figure. 
traps dates $6^{\text {th }}-13^{\text {th }}$ July, $\sim 7$ trap nights, 323 Ae. vexans, $46 \mathrm{n}^{\mathrm{w}}$ ), and for week 31 (estimated traps dates $27^{\mathrm{th}}-31^{\text {st }}$ July, 4 trap nights, 4,600 Ae. vexans, 1,150 $\mathrm{n}^{\mathrm{w}}$ ). Data for Ae. vexans from 2018-2020 is shown in Figure 6, showing the greater numbers collected in 2020.

Larval sampling was conducted throughout various locations on both sides of the River Idle in July and August in each year (2018-2020)) and these were confirmed as Ae. vexans. Larval density was extremely high, however no attempt to assess larval densities or seasonality were performed. Cx. pipiens s.l., Cs. annulata, and Ae. caspius were also collected.

\section{Molecular ID results}

The partial COI regions from ten specimens collected from Gamston were successfully sequenced ( 700 bp). After running a comparison of the sequence information using BLAST $^{\circledast}$ (NCBI), 99 of the most similar matches were determined as Ae. vexans. Sequences with the highest total scores included specimens from Kalenberg, the Netherlands (95\% query cover, 100\% identity. GenBank ref.: MK403237.1, and La Rioja, Spain (95\% query cover, 99.85\% identity. GenBank ref: MK402911.1).

\section{Tahyna virus testing results}

The assay reproducibly detected down to 100 copies/ $\mu \mathrm{l}$ of TAHV RNA as determined by the synthetic standard control. All Ae. vexans extracts tested negative for the presence of TAHV.

\section{River height data}

River height data was sourced from Twyford Bridge monitoring station (latitude: 53.2695, longitude: -0.9519), located on the River Poulter, approximately 200 metres south of the confluence of the River Poulter and the River Idle (Environment Agency, March 2021). In 2019, maximum recorded water levels in May were 0.4 metres, in June $1.2 \mathrm{~m}$ (13 ${ }^{\text {th }}$ June only), July $1.03 \mathrm{~m}$, and August $1.00 \mathrm{~m}$. In 2020 , maximum recorded levels in May were $0.85 \mathrm{~m}$, June $1.5 \mathrm{~m}$ (including daily max. levels $>1.2 \mathrm{~m}$ from $12-30^{\text {th }}$ June), July $1.11 \mathrm{~m}$, and August $1.5 \mathrm{~m}$ (>1.2 m from $17-31^{\text {st }}$ August).

\section{Mosquito control}

In 2019 and 2020, in response to nuisance biting complaints, the local authority treated larval habitats with a liquid Bacillus thuringiensis israelensis (BTI) larvicide (VectoBac ${ }^{\oplus}$ 12AS, Sumitomo Europe (Valent Biosciences Corps), SaintDidier-au-Mont-d'Or, France). From early May in both years officers from the Environmental Health Department at (Bassetlaw District Council) and pest control contractors (Buzzoff Pest Solutions, Doncaster, UK) made weekly visits to site to check for the presence or absence of larvae, with species identified but abundance not quantified. One of the local landowners also agreed to report on larval activity. Application of VectoBac 12AS (1,200 ITU/mg) was made using knapsack sprayers. Dosages of VectoBac 12AS $25 \mathrm{ml} / \mathrm{l}$ were applied to pools of water. Areas which had more vegetation and prone to influx of more water the concentration was increased to $100 \mathrm{ml} / \mathrm{l}$. Due to the sheer size of land it was impossible to spray the whole area

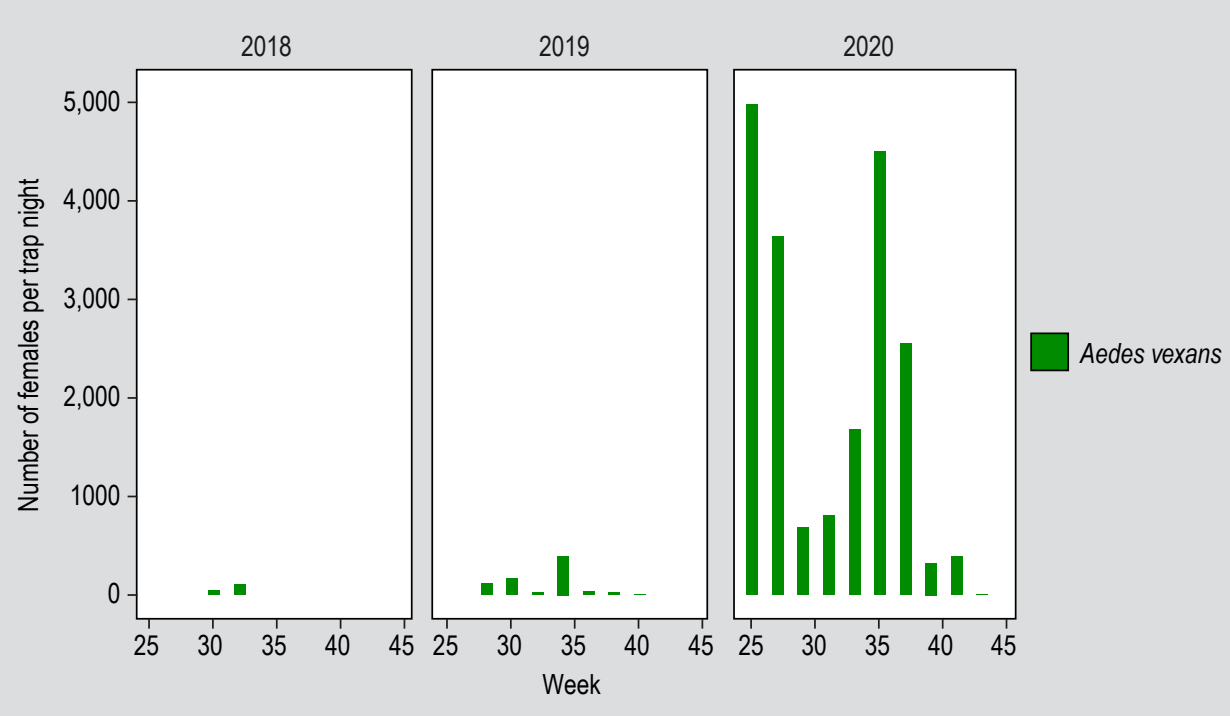

Figure 6. Number of adult female mosquitoes caught per trap night by traps located in Gamston and the River Idle shown by species and year (2018-2020). 
using knapsack sprayers. Site visits were made 24 hours after treatment and a reduction in larvae observed. Water levels were between 10 to $45 \mathrm{~cm}$ in depth where larvae were found. No larvae were observed in open water and were predominately present in grassland vegetation or drainage ditches at the site.

Due to subsidence resulting from now closed underground coal mines in the local area, it was evident where land had sunk on former agricultural land. These areas were found to be prone to standing water and more likely to harbour Ae. vexans larvae. On land on the eastern side of the River Idle (Figure 7 and 8), there was a clear divide between dry and wet areas as a ditch ran through the centre of the land, with the wet areas providing habitat for Ae. vexans. These areas are identified by different grasses as in Figure 6.

In 2020, an area of land west of the River Idle at Dover bottom, adjacent to fishing ponds were also subject to control, particularly the flooded margins of the ponds, where shallow margins allowed a large area to be flooded with a small increase in water levels. A silicon monolayer product (Vazor ${ }^{\oplus}$ Liquid Mosquito Film, distributed by Killgerm Chemicals Ltd, Ossett, UK, manufacturer Selecta $\mathrm{Srl}$, Corsico, Italy) was trialled in these areas in accordance with the manufacturer's instructions $(1 \mathrm{ml}$ undiluted per $\mathrm{m}^{3}$ ) and seen to be effective.

In 2020, an adult mosquito control product was also used in the village, particularly targeting the vegetation, such as hedgerows, bushes and yew trees where Ae. vexans adult mosquitoes were observed to be resting in very high numbers. Vazor Provecta (distributed by Killgerm Chemicals Ltd; manufacturer KB Pharma, Abano Terme, Italy), a polysiloxane product that works by physically immobilising insects, was sprayed once using a recommended manufacturers concentration of $0.1 \%$ ( $10 \mathrm{ml} / 1$ litre water), and according to local residents was effective at reducing
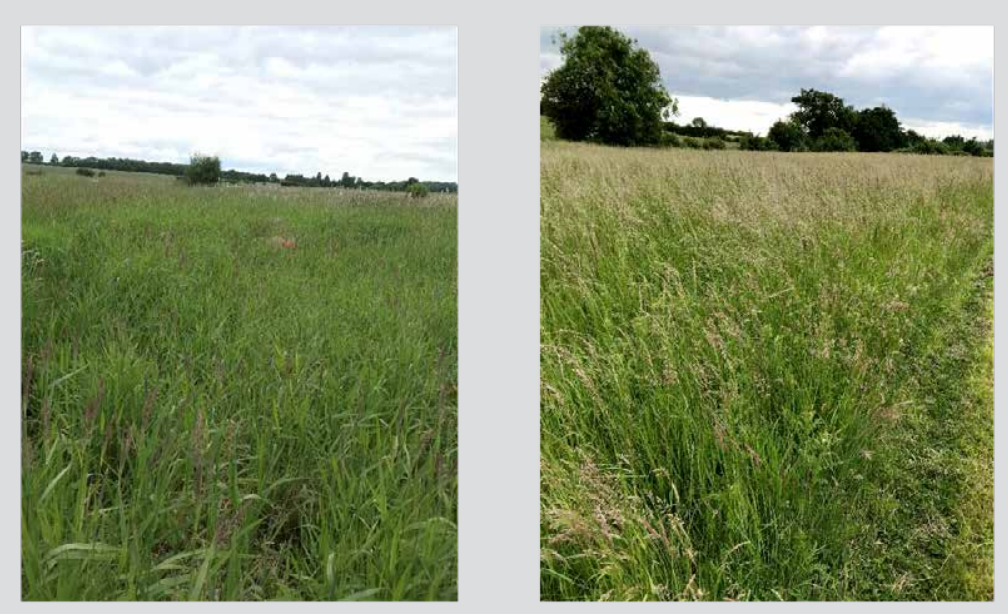

Figure 7. Grassland to the west of the River Idle, showing wet grassland (left) and dry grassland (right), either side of a ditch (August 2019).
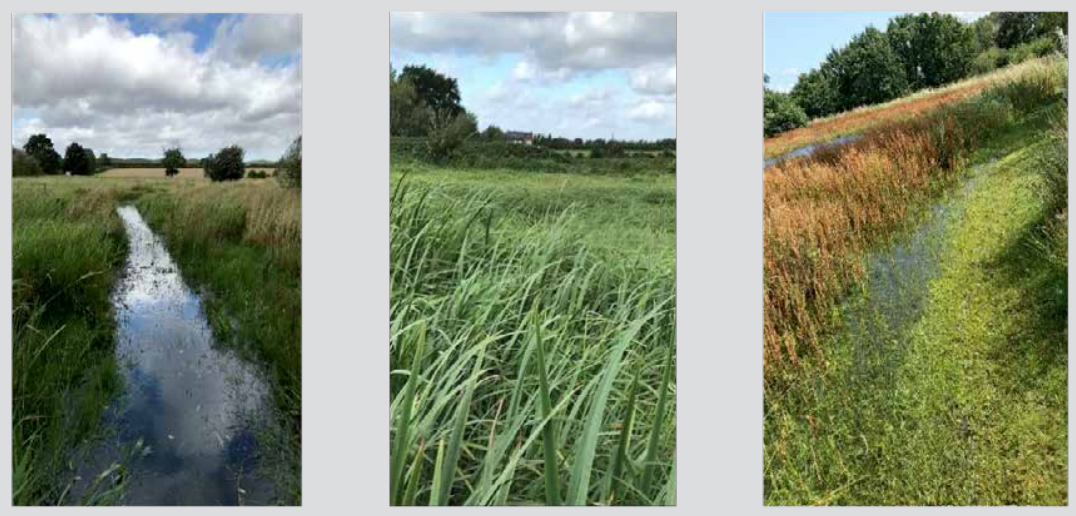

Figure 8. Wet ditch and wet grassland to the east of the River Idle (August 2019). 
numbers of adults present and rates of nuisance biting. This treatment was paid for by the local resident.

\section{Discussion}

The mosquito trapping undertaken at Gamston in 20182020 and reported here demonstrate the very high numbers of $A$ e. vexans in wetlands adjacent to the River Idle near Gamston; a new phenomenon and challenge for the UK. Of particular note are the very high numbers trapped in 2020, and the earlier activity of the species that year, with activity beginning in mid-June in 2020, compared to the second week of July in 2019. This is likely to have been a result of water availability for larval development and timing of river flooding, rather than a strict programmed seasonality, with water levels significantly higher in 2020 compared to 2019. This frequency of high river levels from June-August in 2020, is likely to have caused an increase in wetting and drying cycles, which maintained adult activity at high levels until the end of September, including a second peak of $A e$. vexans adults (week 35 ; beginning $24^{\text {th }}$ August). The adult data presented here however are not directly comparable between years, as traps were not able to be run consistently in the same location. However, the close proximity of the traps at site B (2019) and site C (2020) to the River Idle, do allow a degree of comparison to be made, particularly given the size of the increase in trapped Ae. vexans in 2020 compared to 2019. The data from site A in 2020 allows for a more direct comparison: in week $31\left(27^{\text {th }}-31^{\text {st }} J u l y, 2020\right)$ $1,150 \mathrm{n}^{\mathrm{w}}$ Ae. vexans were trapped, whilst week $32\left(6^{\text {th }}-9^{\text {th }}\right.$ August, 2018) yielded far fewer: $28.5 \mathrm{n}^{\mathrm{w}}$. The occurrence of two seasonal peaks in 2019 and 2020 might suggest at least two peaks of adult activity each year, however it is likely a result of the flooding regime, rather than a bivoltine cycle.

To our knowledge, the rates of adult mosquitoes caught are the highest reported in studies using Mosquito Magnets in the UK. Comparable British studies include surveys targeting Culex modestus in North Kent, where the peak mean abundance per night was $111.4 \mathrm{n}^{\mathrm{w}} C x$. modestus (Vaux et al., 2015), and wet woodland mosquitoes in Woodwalton Fen, Cambridgeshire (Ae. cantans $=230 \mathrm{n}^{\mathrm{w}}$ ) (Medlock and Vaux, 2015). More relevant to Ae. vexans specifically, a trap comparison study in riverine habitats in Germany (Lühken et al., 2014) recorded a total of 1,016 at a Mosquito Magnet over 4 nights $\left(254 \mathrm{n}^{\mathrm{w}}\right)$ - in Gamston 2020 , the highest mean abundance per night across all trap nights was $4,975 \mathrm{n}^{\mathrm{w}}$, significantly higher. Very high rates of floodwater mosquito species (up to 77,000 females per trap night), including Ae. vexans and Aedes sticticus are however frequently reported using other types of traps, such as the CDC light trap (Schäfer and Lundström, 2014; Schäfer et al., 2008), meaning that the rates of Ae. vexans reported in this study are not unexpected in a European context given suitable habitat and flooding regime.
There is strong anecdotal evidence, from local residents, that mosquito biting has been a significant nuisance in Gamston since the early 1990s, but in recent years has become more pronounced, particularly in 2020. The hydrology of the area changed significantly as part of the River Idle Flood Alleviation Scheme in 1997, which restored the meander at the site, and created raised banks and wetlands. The wetland habitats adjacent to the River Idle appear to be favourable to Ae. vexans, and it may be that a change in water levels has facilitated the development of an expanding population, with each year leaving an increasingly larger bank of oviposited eggs within the floodplain substrate, ready for development in following years. Laboratory studies have shown the differing strategies of floodwater species by investigating larval survival and adult emergence rates in response to differing water regimes. These studies showed that in response to drying events, Ae. sticticus accelerated larval development and subsequent adult emergence, whilst $A e$. vexans did not, emerging 6-14 days after complete water removal but soil remaining wet (Schäfer and Lundström, 2006). A 36 year study on the River Rhine reported the need for control treatments after flooding of egg horizons located above, and to the middle, of the water levels. On average there were five flood events per year over the duration of the study (Becker, 1989; Becker et al., 2018). These and other observations from riverine habitats in Europe, show the remarkable ability of Ae. vexans to undergo rapid development in response to flooding events, and demonstrate continued larval development through to adult emergence even in wet soil after waters have receded, but with high mortality (Schäfer and Lundström, 2006). This has significant implications for the management of flood zone habitats.

Discussions between relevant stakeholders and landowners, facilitated by the local authority, are ongoing, with the aim of reducing the mosquito population in the region. Management of floodwater habitat to reduce the area of suitable Ae. vexans habitat will be an important component of these discussions. This could be achieved by: (1) converting flood zones into permanent wetland habitat, providing permanent water pools that could hold additional floodwater without inundating shallow margins and thereby supporting a range of mosquito larvae predators and rendering the habitat less suitable for $A e$. vexans larvae; (2) altering the hydrology of the flooded areas such that there is rapid dewatering following flood events; and (3) building bunds and flood banks to stop water accumulating over large areas, thereby preventing the creation of temporary shallow habitats. The potential of these options depends on local conditions on the ground, as well as stakeholder requirements for land use. Changes to the hydrology of these habitats, including creation of permanent wetland, would also impact the wider flora and fauna, which may benefit some species at the expense of others and this warrants further investigation. Experiences 
and strategies employed by wetland managers of other summer flooded riverine habitats may be applicable in this situation to maximise biodiversity value, which may align with mosquito control strategies by encouraging species that predate on mosquito larvae and adults, or reducing the frequency and intensity of summer flooded events during the peak mosquito season.

Whilst larval control efforts had some success in 2019-2020, larval abundance was not recorded and so control efficacy cannot be assessed. Similarly, the use of a monolayer product targeting larvae and the adult mosquito physical immobilisation silicon product cannot be assessed due to a lack of data. Both of these products are unlikely to be solutions to controlling the bulk of the Ae. vexans population - the former because it is unsuited to large scale vegetated flooded habitats, and the latter due to its impact targeting adults rather than larvae, and potential to impact other non-target species, but each may have its uses as part of a wider control strategy. The use of a BTI larvicide product is currently the best option for large scale larval control, however is limited to the liquid formulation (VectoBac 12AS) as the only BTI product currently licensed for mosquito control in the UK. The use of BTI products is well proven against $A e$ vexans in floodwater habitats, but do require targeted placement and timing (Becker et al., 2018; Schäfer and Lundström, 2014). Larval control must be conducted swiftly following flood events, particularly those events in late spring before the higher summer temperatures which facilitate swifter development. To do this, additional studies are required to further define larval habitats and seasonality in this British wetland, through a programme of larval surveillance and identification. In this way data can be gathered on the species preferred larval habitats and larval mosquito control can be conducted with the aim of reducing early season appearance and subsequent high populations. Access to Ae. vexans larval habitats has proved challenging, given the large area, the relative inaccessibility by foot, alternative strategies such as application by drone may need to be employed to ensure coverage of the control product into larval habitats. Accurate mapping of Ae vexans larval habitats and density are necessary to identify habitats requiring treatment and to establish the correct treatment dosage, and larval instar impact upon treatment efficacy. Treatment of at least $95 \%$ of all larval habitat supporting the species is required to reduce adult abundances down to low population numbers, (Becker and Rettich, 1994; Becker et al., 2003; Schäfer and Lundström, 2014). An integrated approach to the nuisance biting issue in Gamston is therefore needed, to include land and water management, mosquito population assessment, and mosquito control.

\section{References}

Bardos, V. and Danielova, V., 1959. The Tahyna virus - a virus isolated from mosquitoes in Czechoslovakia. Journal of Hygiene, Epidemiology, Microbiology \& Immunology 3: 264-276.

Becker, N., 1989. Life strategies of mosquitoes as an adaptation to their habitats. Bulletin of the Society of Vector Ecologists 14: 6-25.

Becker, N., 1997. Microbial control of mosquitoes: management of the Upper Rhine mosquito population as a model programme. Parasitology Today 13: 485-487. https://doi.org/10.1016/S01694758(97)01154-X

Becker, N., Ludwig, M. and Su, T., 2018. Lack of resistance in Aedes vexans field populations after 36 years of Bacillus thuringiensis subsp. israelensis applications in the upper rhine valley, Germany. Journal of the American Mosquito Control Association 34: 154-157. https://doi.org/10.2987/17-6694.1

Becker, N., Petrić, D., Boase, C. and Lane, J., 2003. Mosquitoes and their control. Springer, Berlin, Germany, 498 pp.

Becker, N. and Rettich, F., 1994. Protocol for the introduction of new Bacillus thuringiensis israelensis products into the routine mosquito control program in Germany. Journal of the American Mosquito Control Association 10: 527-533.

Folmer, O., Black, M., Hoeh, W., Lutz, R. and Vrijenhoek, R., 1994. DNA primers for amplification of mitochondrial cytochrome $\mathrm{c}$ oxidase subunit I from diverse metazoan invertebrates. Molecular Marine Biology and Biotechnology 3: 294-299.

Fortin, J.F. and Slocombe, J.O.D., 1981. Temperature requirements for the development of Dirofilaria immitis in Aedes triseriatus and Ae. vexans. Mosquito News 41: 625-633.

Hendrix, C.M., Bemrick, W.J. and Schlotthauer, J.C., 1980. Natural transmission of Dirofilaria immitis by Aedes vexans. American Journal of Veterinary Research 41: 1253-1255.

Hutchinson, R.A., West, P.A. and Lindsay, S.W., 2007. Suitability of two carbon dioxide-baited traps for mosquito surveillance in the United Kingdom. Bulletin of Entomological Research 97: 591-597. https://doi.org/10.1017/S0007485307005263

Lühken, R., Pfitzner, W.P., Börstler, J., Garms, R., Huber, K., Schork, N., Steinke, S., Kiel, E., Becker, N., Tannich, E. and Krüger, A., 2014. Field evaluation of four widely used mosquito traps in Central Europe. Parasites \& Vectors 7: 268. https://doi.org/10.1186/1756-3305-7-268

Medlock, J.M., Cull, B., Vaux, A.G.C. and Irwin, A.G., 2017. The mosquito Aedes vexans in England. The Veterinary Record 181: 243. https://doi.org/10.1136/vr.j4048

Medlock, J.M., Snow, K.R. and Leach, S., 2007. Possible ecology and epidemiology of medically important mosquito-borne arboviruses in Great Britain. Epidemiology and Infection 135: 466-482. https:// doi.org/10.1017/S0950268806007047

Medlock, J.M. and Vaux, A.G.C., 2015. Seasonal dynamics and habitat specificity of mosquitoes in an English wetland - implications for UK wetland management and restoration. Journal of Vector Ecology 40: 90-106. https://doi.org/10.1111/jvec.12137

\section{Conflict of interest}

The authors declare no competing interests. 
Miller, B.R., Godsey, M.S., Crabtree, M.B., Savage, H.M., Al-Mazrao, Y., Al-Jeffri, M.H., Abdoon, A.M., Al-Seghayer, S.M., Al-Shahrani, A.M. and Ksiazek, T.G., 2002. Isolation and genetic characterization of Rift Valley fever virus from Aedes vexans arabiensis, Kingdom of Saudi Arabia. Emerging Infectious Diseases 8: 1492-1494. https:// doi.org/10.3201/eid0812.020194

Napp, S., Petrić, D. and Busquets, N., 2018. West Nile virus and other mosquito-borne viruses present in Eastern Europe. Pathogens and Global Health 112: 233-248.

Petrić, D., Zgomba, M., Bellini, R., Veronesi, R., Kaiser, A. and Becker, N., 1999. Validation of $\mathrm{CO}_{2}$ trap data in three European regions. In: Robinson, W.H., Retich, F. and Rambo, G.W. (eds.) Proceedings of the $3^{\text {rd }}$ International Conference on Urban Pests. 19-22 July 1999. Prague, Czech Republic, pp. 437-445.

Schäfer, M., Lundström, J. and Petersson, E., 2008. Comparison of mosquito (Diptera: Culicidae) populations by wetland type and year in the lower River Dalälven region, Central Sweden. Journal of Vector Ecology 33: 150-157. https://doi.org/10.3376/10811710(2008)33[150:comdcp]2.0.co;2
Schäfer, M.L. and Lundström, J.O., 2006. Different responses of two floodwater mosquito species, Aedes vexans and Ochlerotatus sticticus (Diptera: Culicidae), to larval habitat drying. Journal of Vector Ecology 31: 123-128. https://doi.org/10.3376/10811710(2006)31[123:DROTFM]2.0.CO;2

Schäfer, M.L. and Lundström, J.O., 2014. Efficiency of Bti-based floodwater mosquito control in Sweden: four examples. Journal of the European Mosquito Control Association 32: 1-8.

Snow, K.R., 1990. Mosquitoes. Richmond Publishing, London, UK. Vaux, A.G., Gibson, G., Hernandez-Triana, L.M., Cheke, R.A., McCracken, F., Jeffries, C.L., Horton, D.L., Springate, S., Johnson, N., Fooks, A.R., Leach, S. and Medlock, J.M., 2015. Enhanced West Nile virus surveillance in the North Kent marshes, UK. Parasites \& Vectors 8: 91. https://doi.org/10.1186/s13071-015-0705-9

Weidmann, M., Rudaz, V., Nunes, M.R., Vasconcelos, P.F. and Hufert, F.T., 2003. Rapid detection of human pathogenic orthobunyaviruses. Journal of Clinical Microbiology 41: 3299-3305. https://dx.doi. org/10.1128/JCM.41.7.3299-3305.2003 
